\title{
High intake of added sugar among Norwegian children and adolescents
}

\author{
Nina C Øverby ${ }^{1, *}$, Inger TL Lillegaard ${ }^{1}$, Lars Johansson ${ }^{2}$ and Lene F Andersen ${ }^{1}$ \\ 'Institute for Nutrition Research, University of Oslo, Box 1046, Blindern, N-0316 Oslo, Norway: \\ ${ }^{2}$ Directorate for Health and Social Affaires, Oslo, Norway
}

Submitted 24 February 2003: Accepted 2 July 2003

\begin{abstract}
Objective: It is debated whether the intake of added sugar displaces micronutrientrich foods and dilutes the nutrient density of the diet, and whether there is a link between sugar and the increased rate of obesity. The objectives of this study were to examine the effect of added sugar on the intakes of energy, micronutrients, fruit and vegetables, and to examine the association between intake of added sugar and age, sex, body mass index, physical activity, inactivity and parents' education.

Design: Participants recorded their food intake in pre-coded food diaries for 4 days and filled in a questionnaire about physical activity, watching television (TV)/using a personal computer (PC) and parents' education.

Subjects: Three hundred and ninety-one 4-year-olds, 810 students in the 4 th grade (9 years old) and 1005 in the 8 th grade (13 years old) were included in the study.

Results: The intakes of all nutrients, except $\alpha$-tocopherol among 4-year-olds and vitamin $\mathrm{C}$ among 4-year-olds and 4th graders, decreased with increasing content of added sugar in the diet. Moreover, high consumers of added sugar had a $30-40 \%$ lower intake of fruit and vegetables than did low consumers. A negative association was observed between consumption of added sugar and body mass index among girls in the 8th grade $(P=0.013)$, whereas a positive association was observed among 4-year-old boys $(P=0.055)$. Associations between physical activity, hours spent watching TV/using a PC, parents' education and the energy intake from added sugar varied in the different age groups.

Conclusions: This study showed a negative association between the intake of added sugar and intakes of micronutrients, fruit and vegetables. The negative association between sugar intake and intake of fruit and vegetables is important from a public health perspective, since one of the main health messages today is to increase current intake of fruit and vegetables.
\end{abstract}

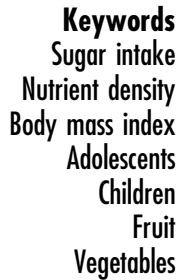

It is debated whether the intake of added sugar displaces micronutrient-rich foods and dilutes the nutrient density of the $\operatorname{diet}^{1-8}$, and furthermore whether there is a link between sugar and the increased rate of obesity ${ }^{2,3}$. In the Nordic countries it is recommended to limit added sugar to a maximum of $10 \%$ of total energy intake for children and for adults with a low energy intake?. The arguments for having these guidelines are that sugar is the main cause of dental caries, and that a high intake of sugar may displace micronutrient-rich foods from the diet and make it difficult to achieve sufficient intakes of nutrients and dietary fibre? In the case of dental caries there is consensus about the relationship between frequency of sugar intake and the incidence of decay ${ }^{10,11}$. However, there is no consensus in the literature on whether high consumption of sugar displaces micronutrient-rich foods from the diet and decreases the intakes of essential nutrients. Several researchers have reported a higher intake of essential nutrients with increasing sugar intake ${ }^{1-5}$, while others have reported a clear negative effect of sugar intake on nutrient density ${ }^{2,6-8}$. Only a few studies have looked at the association between added sugar intake and intakes of fruit and vegetables ${ }^{1,2,5}$. The beneficial health effects of a high intake of fruit and vegetables are well known and a low intake of these food items may be negative for health even if the intakes of micronutrients are acceptable ${ }^{12,13}$.

During past decades, body weight has increased among adolescents world-wide ${ }^{14}$. High intakes of fat, sugar, junk foods and soft drinks, and low physical activity, are some factors suggested to have caused this increase. Only a few studies have evaluated the association between body mass index (BMI) and sugar intake among children and adolescents $^{2,3,15}$. Lewis et al. $^{2}$ found that children with a high percentage of energy from added sugar tended to weigh less than children with a moderate consumption of added sugar, while Ludwig et al. ${ }^{15}$ found that, for each 
additional serving of sugar-sweetened drink consumed, BMI and frequency of obesity increased.

In the present study we evaluated whether a high added sugar intake reduces the intakes of essential nutrients and the intake of fruit and vegetables among children and adolescents. Furthermore, we wanted to see if there was an association between intake of sugar and age, sex, BMI, physical activity, inactivity and parents' education.

\section{Methods}

\section{Subjects}

A random, nationally representative sample of 106 schools (53 primary and 53 secondary schools) from 53 municipalities was drawn by Statistics Norway to participate in this study. Nine schools refused to participate, and seven other randomly chosen schools in the same municipality were included. One school completed their recording too late to be included in the survey. In total, 103 of 106 schools and 1835 of 2214 invited students responded, which represents a participation rate of $83 \%$. A total of 20 students were excluded, 14 because they only recorded their intake for 3 days and six because they were only 3 rd graders. The final sample consisted of 1815 children, 810 in the 4 th grade ( 9 years old) and 1005 in the 8th grade (13 years old), with a participation rate of $81 \%$ and $84 \%$ for the 4 th and 8 th grade, respectively.

Four-year-olds were recruited through child health centres. Statistics Norway established a sample of child health centres in 11 urban and 22 rural municipalities. Child health centres in nine urban and 18 rural municipalities wanted to participate in the study. Centres that did not wish to participate were replaced by new centres. In total 38 child health centres were included in the analysis, 25 from rural and 13 from urban municipalities. Invitation letters were sent to 746 4-year-olds, of these 126 did not meet at their health control at the child health centre and could not participate. Information was given to 5114 -year-olds, whereof 394 completed the food recording. Three children were excluded, two because they were ill during recording and one because the diaries were not filled in correctly. The final sample consisted of 3914 -year-olds, which represents a participation rate of $52 \%$.

The regional ethical committee approved the study. Informed consent was obtained from the parents and the 13-year-old students.

\section{Design}

Data collection among students in the 4th and 8th grades was carried out from September to the first week of December 2000. The students received an invitation letter and a short frequency questionnaire at school approximately two weeks before food recording started. Children and parents who wanted to participate returned the questionnaire and informed consent to the University of Oslo. A nutritionist visited each class and gave oral and written instructions on how the diet should be registered. The participants received four food diaries, a booklet regarding portion sizes and written instructions.

Data collection among the 4-year-olds was carried out from August to the first week of December 2001. The participating child health centres included an invitation letter to the present study in the invitation for health control at 4 years of age. Parents who wanted their child to participate returned the questionnaire and informed consent at the child health centre when they came for health control, and met a nutritionist for instructions on how the diet should be recorded.

All participants were phoned on the second day of their recording period, to encourage and answer questions. Participants could call the nutritionist at any time with questions.

\section{Food diary}

The participants recorded their entire food intake for four consecutive days in an 18-page pre-coded food diary. The 4-day period consisted of three weekdays and one weekend day. Participants in the 8th grade recorded their diet themselves, while parents filled in the diary for the 4-year-olds and students in the 4 th grade.

The diary had lists of 277 drinks, food items and dishes grouped together according to a typical Norwegian diet. Each food group was supplemented with open-ended alternatives. The design of the pre-coded food diary was similar to a cross-table, with food listed on the left and time span on the top. Food amounts were presented in predefined household units (e.g. beverage is recorded in glasses, bread in slices) or as portions estimated from photographs. Along with the diary each participant received a photographic booklet which embodied 13 colour photograph series, each with four different portion sizes ranging from small to large. The photographic booklet has been evaluated and the results will be published elsewhere. The participants indicated an eating event by filling in how many units they had eaten of each food item in the correct time span. The day was divided into five time spans (from 06.00 to 10.00 , from 10.00 to 14.00 , etc.).

\section{Calculations of dietary intake}

Data were entered by scanning, using the Teleform program (6.0) (Datascan, Oslo, Norway). Daily intakes of foods, energy and nutrients were computed using a food database and software system developed at the Institute of Nutrition Research, University of Oslo. The food database is mainly based on the official food composition table ${ }^{16}$, and is continuously supplemented with data on new food items and nutrients. Corrections for losses in cooking are done when calculating nutrient contents. The use of cod 
liver oil, vitamin and mineral preparations was not included in the nutrient calculation.

\section{Short questionnaire}

The short questionnaire contained questions about height, weight, physical activity, time spent watching television (TV)/using a personal computer (PC), and parents' education. Data on weight and height were given by 290 (74\%), 664 (82\%) and 825 (82\%) of the 4-year-olds, 4th and 8 th graders, respectively.

Estimates of basal metabolic rate (BMR) were calculated from equations based on weight, age and $\operatorname{sex}^{17}$. A comparison of energy intakes with estimates of BMR was used to calculate the number of respondents who underreported their energy intake. A ratio between energy intake and BMR of less than 1.06 may indicate underreporting of energy intake ${ }^{18}$.

The participants reported how often they watched TV/used a PC each day. The answers were split into three categories: (1) watch TV/use PC for $1 \mathrm{~h}$ or less per day, (2) watch TV/use PC for $2-3 \mathrm{~h}$ per day and (3) watch TV/use PC for $4 \mathrm{~h}$ per day or more. The question about how often the participants exercised was categorised into (1) active 3 times per month or less, (2) active 1-3 times per week and (3) active 4-7 times per week.

Parents were asked about their education. Two categories were formed from this question: short education (12 years of school or less) and long education (13 years of school or more).

\section{Definitions}

The term 'added sugar' refers to refined or industrially produced sugar used as an ingredient in processed or prepared foods such as cakes and cookies, soft drinks and ice cream, or added at home in the kitchen or at the table 9 . Added sugar does not include naturally occurring mono- and disaccharides in fruits, juices and milk.

The percentage of overweight children was estimated using Cole et al.'s definitions of overweight according to age ${ }^{19}$.

\section{Statistical analysis}

Sample means with standard deviation are presented. Differences between means were tested with the Independent-samples $t$-test. To analyse the consequences of high sugar intake, children were divided into quartiles of percentage energy from added sugar. Differences between quartiles were assessed by one-way analysis of variance. For further analysis the lowest and highest quartiles of percentage energy from added sugar are compared, which are referred to hereafter as low and high added sugar consumers, respectively. To test the relationship between categorical variables the Chi-square test for independence was used. Data are presented for the three different age groups and are not separated by gender. However, when differences between boys and girls were found, these are commented on in the text. Significance levels were two-sided. Data were analysed using SPSS 11.0 (SPSS, Inc., Chicago, IL, USA).

\section{Results}

The intake of energy from added sugar increased from 4year-olds to students in the 8 th grade $(P<0.000)$. On average, 4 -year-olds and students in the 4 th and 8 th grades had a mean added sugar intake of 55, 80 and $95 \mathrm{~g} \mathrm{day}^{-1}$, respectively, accounting for 15.1, 16.8 and $18.4 \%$ of energy intake.

Mean intakes of energy, macro- and micronutrients across the quartiles of percentage of energy from added sugar are given in Tables $1-3$. There were no significant differences in energy intake across the quartiles of added sugar for all age groups. The intakes of all nutrients, except vitamin $\mathrm{C}$ among 4 -year-olds and 4th graders and $\alpha$ tocopherol among 4-year-olds, decreased from the lowest to the highest quartile of added sugar intake. The difference in micronutrient intake between the lowest and highest quartile of added sugar ranged from 1 to $42 \%$. The largest difference was observed for vitamin D among 8th graders, the high consumers of added sugar having a $42 \%$ lower intake of vitamin D than the low consumers. Most of the differences in micronutrient intake between low and high added sugar consumers were above $20 \%$. Comparing intakes in the quartiles with the recommendations ${ }^{9}$, it was found that the average intakes of dietary fibre, $\alpha$-tocopherol, vitamin D and iron were lower than the recommendations in all quartiles and age groups. Among 8th graders the intakes of calcium, retinol equivalents and thiamin were at the recommended level in the lowest quartile of added sugar intake but below the recommendations in the highest added sugar quartile. This was also observed for thiamin among 4-year-olds and 4th graders. The intakes of riboflavin among 4-year-olds and 4th graders and vitamin $\mathrm{C}$ in all age groups were at recommended levels in all quartiles. When supplements were included the same decrease of nutrient intakes across the quartiles of added sugar as discussed above was observed. However, the intakes of vitamin D and iron were at the recommended levels in the first and second quartile of sugar intake for all age groups; this was not observed in the results without supplements.

The total intake of fruit and vegetables decreased with increased intake of added sugar for all age groups (Tables 1-3). Total intake of fruit and vegetables for 4-year-olds was 37\% lower among the children in the highest quartile of added sugar intake compared with children in the lowest quartile. The corresponding percentage for 4 th graders was $33 \%$ and $42 \%$ for 8 th graders. Looking at fruit and vegetables separately, the same decrease in intake across quartiles of added sugar intake was observed; however, only borderline significant for fruit among 4-year-olds. Intake of vegetables 
Table 1 Intakes of energy, nutrients and selected foods in quartiles of energy from added sugar, 4-year-olds (supplements not included). Values are expressed as mean (standard deviation)

\begin{tabular}{|c|c|c|c|c|c|c|c|}
\hline & \multicolumn{4}{|c|}{ Percentage energy from added sugar } & \multirow[b]{2}{*}{$P$-value } & \multirow[b]{2}{*}{$\begin{array}{c}\text { Q1-Q4 } \\
\text { (\% difference) } \ddagger\end{array}$} & \multirow[b]{2}{*}{ NNR§ } \\
\hline & $\begin{array}{c}\mathrm{Q1}^{*} \\
<11.4 \\
(n=97)\end{array}$ & $\begin{array}{c}\mathrm{Q}^{*} \\
11.4-14.6 \\
(n=98)\end{array}$ & $\begin{array}{c}\text { Q3* }^{\star} \\
14.6-18.4 \\
(n=98)\end{array}$ & $\begin{array}{c}\mathrm{Q}^{*} \\
>18.4 \\
(n=98)\end{array}$ & & & \\
\hline Energy (MJ) & $6.2(1.3)$ & $6.1(1.3)$ & $6.4(1.4)$ & $6.1(1.4)$ & 0.447 & - & $6.8 / 7.19$ \\
\hline Protein (\% energy) & $15.7(2.2)$ & $14.4(2.1)$ & $13.7(1.7)$ & $12.5(1.8)$ & 0.000 & - & - \\
\hline Fat (\% energy) & $34.7(4.4)$ & $32.6(4.5)$ & $32.7(4.7)$ & $29.8(4.3)$ & 0.000 & - & - \\
\hline Saturated fat (\% energy) & $15.1(2.5)$ & $14.1(2.5)$ & $14.4(2.2)$ & $13.1(2.2)$ & 0.000 & - & \\
\hline Carbohydrates (\% energy) & $49.6(4.9)$ & $53.0(4.7)$ & $53.6(4.7)$ & $57.7(4.5)$ & 0.000 & - & - \\
\hline Added sugar ( $\%$ energy) & $8.8(2.0)$ & $13.0(0.9)$ & $16.4(1.1)$ & $22.3(4.2)$ & 0.000 & - & - \\
\hline Fibre (g) & $13.8(6.1)$ & $12.4(4.0)$ & $11.2(3.5)$ & $10.2(3.4)$ & 0.000 & 26 & $3 \mathrm{gMJ}^{-1}$ \\
\hline Retinol equivalents $(\mu \mathrm{g})$ & $1075(541)$ & $990(1250)$ & 817 (400) & $744(400)$ & 0.006 & 31 & 500 \\
\hline$\alpha$-Tocopherol $(\mu \mathrm{g})$ & $4.8(1.5)$ & $4.6(1.3)$ & $4.5(1.5)$ & $4.2(1.4)$ & 0.083 & 13 & 6 \\
\hline Vitamin $D(\mu \mathrm{g})$ & $2.9(2.4)$ & $2.6(1.6)$ & $2.5(1.8)$ & $2.2(1.7)$ & 0.050 & 24 & 5 \\
\hline Thiamin (mg) & $0.9(0.2)$ & $0.9(0.2)$ & $0.8(0.2)$ & $0.7(0.2)$ & 0.000 & 22 & 0.8 \\
\hline Riboflavin (mg) & $1.3(0.3)$ & $1.2(0.3)$ & $1.3(0.4)$ & $1.1(0.3)$ & 0.000 & 15 & 1.0 \\
\hline Vitamin C (mg) & $68(32)$ & $66(31)$ & $62(29)$ & $69(33)$ & 0.470 & 1 & 45 \\
\hline Calcium (mg) & $730(225)$ & $650(176)$ & $710(208)$ & $605(212)$ & 0.000 & 17 & 600 \\
\hline Iron (mg) & $7.1(2.4)$ & $6.8(2.0)$ & $6.6(2.1)$ & $5.9(1.7)$ & 0.001 & 16 & 8 \\
\hline Fruit and vegetables (g) & 277 (142) & $251(133)$ & $198(127)$ & $174(106)$ & 0.000 & 37 & - \\
\hline Fruit (g) & $101(71)$ & $81(61)$ & $64(48)$ & $73(57)$ & 0.070 & 28 & - \\
\hline Vegetables (g) & $75(63)$ & $57(36)$ & $45(45)$ & $41(40)$ & 0.000 & 45 & - \\
\hline Fruit juices (g) & $59(77)$ & $80(92)$ & $63(90)$ & $40(61)$ & 0.007 & 32 & - \\
\hline Potatoes $(\mathrm{g})$ & $41(43)$ & $34(32)$ & $26(27)$ & $21(26)$ & 0.000 & 49 & - \\
\hline
\end{tabular}

* Quartiles of percentage of energy consumed from added sugar.

tOne-way analysis of variance.

† Percentage difference between Q1 and Q4 in micronutrient intake (Q1-Q4/Q1).

$\S$ Nordic Nutrition Recommendations.

ๆ Recommendations for girls/boys.

Table 2 Intakes of energy, nutrients and selected foods in quartiles of energy from added sugar, 4th graders (supplements not included). Values are expressed as mean (standard deviation)

\begin{tabular}{|c|c|c|c|c|c|c|c|}
\hline & \multicolumn{4}{|c|}{ Percentage energy from added sugar } & \multirow[b]{2}{*}{$P$-valuet } & \multirow[b]{2}{*}{$\begin{array}{c}\text { Q1-Q4 } \\
\text { (\% difference)ł }\end{array}$} & \multirow[b]{2}{*}{ NNR§ } \\
\hline & $\begin{array}{c}\mathrm{Q}^{*} \\
<12.6 \\
(n=202)\end{array}$ & $\begin{array}{c}\mathrm{Q}^{*} \\
12.7-16.5 \\
(n=203)\end{array}$ & $\begin{array}{c}\mathrm{Q}^{*} \\
16.6-20.2 \\
(n=203)\end{array}$ & $\begin{array}{c}\mathrm{Q}^{*} \\
>20.2 \\
(n=202)\end{array}$ & & & \\
\hline Energy (MJ) & $8.2(2.2)$ & $8.3(2.1)$ & $8.2(1.8)$ & $8.0(2.1)$ & 0.406 & - & $7.5 / 8.59$ \\
\hline Protein (\% energy) & $16.0(2.5)$ & $14.6(2.1)$ & $14.0(2.0)$ & $12.6(1.9)$ & 0.000 & - & - \\
\hline Fat ( $\%$ energy) & $34.3(5.5)$ & $32.2(4.8)$ & $31.3(3.9)$ & $28.5(5.1)$ & 0.000 & - & - \\
\hline Saturated fat (\% energy) & $14.6(2.6)$ & $13.9(2.4)$ & $13.7(2.2)$ & $12.6(2.6)$ & 0.000 & - & \\
\hline Carbohydrates (\% energy) & $49.8(5.9)$ & $53.2(5.1)$ & $54.7(4.0)$ & $58.9(5.7)$ & 0.000 & - & - \\
\hline Added sugar (\% energy) & $9.5(2.5)$ & $14.6(1.1)$ & $18.4(1.0)$ & $24.6(4.4)$ & 0.000 & - & - \\
\hline Fibre $(\mathrm{g})$ & $17.1(8.7)$ & $15.4(5.9)$ & $14.0(5.1)$ & $12.7(5.2)$ & 0.000 & 26 & $25-35$ \\
\hline Retinol equivalents $(\mu \mathrm{g})$ & 1160 (672) & 1050 (602) & 990 (612) & 775 (524) & 0.000 & 33 & 700 \\
\hline$\alpha$-Tocopherol $(\mu \mathrm{g})$ & $6.4(2.6)$ & $6.4(2.3)$ & $6.0(1.9)$ & $5.5(1.9)$ & 0.000 & 14 & 7 \\
\hline Vitamin D $(\mu \mathrm{g})$ & $3.4(2.7)$ & $2.9(2.4)$ & $2.7(1.9)$ & $2.2(1.7)$ & 0.000 & 35 & 5 \\
\hline Thiamin (mg) & $1.3(0.4)$ & $1.2(0.3)$ & $1.1(0.3)$ & $0.9(0.3)$ & 0.000 & 31 & 1.0 \\
\hline Riboflavin (mg) & $1.6(0.5)$ & $1.5(0.5)$ & $1.4(0.4)$ & $1.4(0.7)$ & 0.000 & 25 & 1.1 \\
\hline Vitamin C (mg) & $85(53)$ & $86(49)$ & $84(38)$ & $82(38)$ & 0.834 & 4 & 45 \\
\hline Calcium (mg) & $930(345)$ & $880(325)$ & $803(276)$ & $730(280)$ & 0.000 & 22 & 700 \\
\hline Iron (mg) & $9.6(3.5)$ & $9.1(2.8)$ & $8.5(2.5)$ & $7.9(2.5)$ & 0.000 & 18 & 10 \\
\hline Fruit and vegetables (g) & 291 (205) & $265(168)$ & $248(136)$ & 196 (122) & 0.000 & 33 & - \\
\hline Fruit (g) & $94(112)$ & $73(66)$ & $74(75)$ & $63(57)$ & 0.044 & 33 & - \\
\hline Vegetables (g) & $73(70)$ & 75 (76) & $64(56)$ & $50(43)$ & 0.000 & 32 & - \\
\hline Fruit juices (g) & 79 (125) & $72(120)$ & $69(92)$ & $54(88)$ & 0.110 & 32 & - \\
\hline Potatoes $(\mathrm{g})$ & $45(43)$ & $45(42)$ & $40(37)$ & $29(36)$ & 0.000 & 36 & - \\
\hline
\end{tabular}

${ }^{*}$ Quartiles of percentage of energy consumed from added sugar.

† One-way analysis of variance.

† Percentage difference between Q1 and Q4 in micronutrient intake (Q1-Q4/Q1)

$\S$ Nordic Nutrition Recommendations.

I Recommendations for girls/boys. 
Table 3 Intakes of energy, nutrients and selected foods in quartiles of energy from added sugar, 8th graders (supplements not included). Values are expressed as mean (standard deviation)

\begin{tabular}{|c|c|c|c|c|c|c|c|}
\hline & \multicolumn{4}{|c|}{ Percentage energy from added sugar } & \multirow[b]{2}{*}{$P$-value $†$} & \multirow[b]{2}{*}{$\begin{array}{c}\text { Q1-Q4 } \\
\text { (\% difference) } \ddagger\end{array}$} & \multirow[b]{2}{*}{ NNR§ } \\
\hline & $\begin{array}{c}\mathrm{Q1}^{*} \\
<13.4 \\
(n=251)\end{array}$ & $\begin{array}{c}\mathrm{Q} 2^{*} \\
13.4-18.0 \\
(n=203)\end{array}$ & $\begin{array}{c}\mathrm{Q3}^{\star} \\
18.1-22.8 \\
(n=203)\end{array}$ & $\begin{array}{c}\mathrm{Q}^{*} \\
>22.8 \\
(n=251)\end{array}$ & & & \\
\hline Energy (MJ) & $8.7(3.0)$ & $9.0(3.5)$ & $8.6(2.8)$ & 8.7 (3.3) & 0.456 & - & 8.4/9.8ף \\
\hline Protein (\% energy) & $16.8(3.2)$ & $14.9(2.4)$ & $13.9(2.4)$ & $12.3(2.4)$ & 0.000 & - & - \\
\hline Fat (\% energy) & $33.0(5.6)$ & $31.7(5.1)$ & $30.3(4.4)$ & $27.5(4.8)$ & 0.000 & - & - \\
\hline Saturated fat (\% energy) & $14.2(2.9)$ & $13.9(2.5)$ & $13.4(2.4)$ & $12.3(2.7)$ & 0.002 & - & - \\
\hline Carbohydrates (\% energy) & $50.2(6.2)$ & $53.4(5.4)$ & $55.8(4.6)$ & $60.2(5.5)$ & 0.000 & - & - \\
\hline Added sugar ( $\%$ energy) & $9.8(2.8)$ & $15.9(1.3)$ & $20.2(1.3)$ & $27.9(4.7)$ & 0.000 & - & - \\
\hline Fibre (g) & $17.4(8.9)$ & $16.3(8.3)$ & $13.6(5.6)$ & $12.1(6.1)$ & 0.000 & 30 & $25-35$ \\
\hline Retinol equivalents $(\mu \mathrm{g})$ & $1240(3120)$ & 890 (590) & $850(960)$ & $770(1410)$ & 0.020 & 39 & $800 / 9001$ \\
\hline$\alpha$-Tocopherol $(\mu \mathrm{g})$ & $7.5(3.8)$ & $7.3(4.0)$ & $6.7(3.5)$ & $6.0(3.5)$ & 0.000 & 20 & 8 \\
\hline Vitamin D $(\mu \mathrm{g})$ & $3.1(3.3)$ & $3.0(3.1)$ & $2.3(2.2)$ & $1.8(1.6)$ & 0.000 & 42 & 5 \\
\hline Thiamin (mg) & $1.3(0.5)$ & $1.2(0.5)$ & $1.1(0.4)$ & $0.9(0.5)$ & 0.000 & 31 & $1.0 / 1.2 \rrbracket$ \\
\hline Riboflavin (mg) & $1.6(0.7)$ & $1.5(0.7)$ & $1.3(0.5)$ & $1.2(0.6)$ & 0.000 & 25 & $1.2 / 1.49$ \\
\hline Vitamin C (mg) & $95(58)$ & $96(67)^{\prime}$ & $85(55)$ & $81(49)$ & 0.006 & 15 & 50 \\
\hline Calcium (mg) & $960(449)$ & 900 (439) & $810(400)$ & $760(440)$ & 0.000 & 21 & 900 \\
\hline Iron (mg) & $10.5(4.1)$ & $9.8(4.4)$ & $8.8(3.0)$ & $8.6(3.6)$ & 0.000 & 18 & $12-18 / 129$ \\
\hline Fruit and vegetables (g) & 317 (228) & 288 (229) & 230 (172) & $185(144)$ & 0.000 & 42 & - \\
\hline Fruit $(\mathrm{g})$ & $75(98)$ & $60(75)$ & $54(68)$ & $35(55)$ & 0.000 & 53 & - \\
\hline Vegetables (g) & $89(101)$ & $80(77)$ & $60(57)$ & $49(50)$ & 0.000 & 45 & - \\
\hline Fruit juices (g) & $102(160)$ & 99 (158) & $78(131)$ & $65(107)$ & 0.009 & 36 & - \\
\hline Potatoes $(\mathrm{g})$ & $50(48)$ & $49(54)$ & $37(40)$ & $36(45)$ & 0.000 & 28 & - \\
\hline
\end{tabular}

* Quartiles of percentage of energy consumed from added sugar.

† One-way analysis of variance.

$\ddagger$ Percentage difference between Q1 and Q4 in micronutrient intake (Q1-Q4/Q1).

$\S$ Nordic Nutrition Recommendations.

ๆ Recommendations for girls/boys.

decreased by $45 \%$ for both 4 -year-olds and 8 th graders from the lowest to the highest quartile of added sugar intake.

Sources of added sugar were quite similar between the low and high groups of added sugar consumers, although the proportions from different sources varied (Table 4). Among children with a high intake of sugar, soft drinks contributed $46-53 \%$ of the intake of added sugar, while soft drinks contributed $25-36 \%$ of the added sugar among children with a lower intake of added sugar. Low added sugar consumers had a higher proportion of added sugar from dairy products than did the high consumers of added sugar $(12-22 \%$ vs. $5-11 \%)$.

BMI and percentage of overweight children among low and high added sugar consumers are presented in Tables 5 and 6. No differences were found between low and high added sugar consumers regarding BMI and proportions of overweight, except for BMI among girls in the 8th grade $(P=0.013$, Table 5) and among 4-year-old boys $(P=0.055$, Table 6). Low added sugar consumers among girls in the 8th grade had a higher BMI than those who were high added sugar consumers. The opposite was observed among 4-year old boys, where low added sugar consumers had a lower BMI than high added sugar consumers. Moreover, no significant differences were found in the proportions of underreporters of energy intake between high and low added sugar consumers in all age groups, but the proportions of underreporters were much higher among 8th graders than among the other age groups.

Among 4-year-olds with low added sugar intake, a higher percentage of mothers had long education (61\%)

Table 4 Mean contribution (\%) of added sugar in the diet from different food groups in the low and high added sugar consumer groups

\begin{tabular}{|c|c|c|c|c|c|c|c|c|c|}
\hline & \multicolumn{3}{|c|}{ 4-year-olds } & \multicolumn{3}{|c|}{ 4th graders } & \multicolumn{3}{|c|}{ 8th graders } \\
\hline & $\begin{array}{c}\mathrm{Q1}^{*} \\
(n=97)\end{array}$ & $\begin{array}{c}\mathrm{Q}^{*} \\
(n=98)\end{array}$ & $P$-value $\dagger$ & $\begin{array}{c}\mathrm{Q1}^{*} \\
(n=202)\end{array}$ & $\begin{array}{c}\mathrm{Q}^{*} \\
(n=202)\end{array}$ & $P$-value $†$ & $\begin{array}{c}\mathrm{Q}^{*} \\
(n=251)\end{array}$ & $\begin{array}{c}\text { Q4* }^{*} \\
(n=251)\end{array}$ & $P$-value $\dagger$ \\
\hline Soft drinks/lemonade & 25 & 46 & 0.000 & 31 & 47 & 0.000 & 36 & 53 & 0.000 \\
\hline Sugar \& sweets & 23 & 20 & 0.098 & 28 & 27 & 0.788 & 25 & 27 & 0.160 \\
\hline Cakes & 11 & 10 & 0.319 & 10 & 7 & 0.003 & 9 & 6 & 0.000 \\
\hline Dairy products & 22 & 11 & 0.000 & 12 & 6 & 0.000 & 12 & 5 & 0.000 \\
\hline Jam & 8 & 6 & 0.072 & 8 & 4 & 0.000 & 6 & 2 & 0.000 \\
\hline Other products & 10 & 9 & 0.348 & 12 & 8 & 0.008 & 11 & 6 & 0.000 \\
\hline
\end{tabular}

* First and fourth quartile of percentage of energy consumed from added sugar.

†Two-sample $t$-test. 
Table 5 Distribution of BMI (mean (standard deviation)) and percentage of overweight and underreporters among low and high added sugar consumers (girls)

\begin{tabular}{|c|c|c|c|c|c|c|c|c|c|}
\hline & \multicolumn{3}{|c|}{ 4-year-olds } & \multicolumn{3}{|c|}{ 4th graders } & \multicolumn{3}{|c|}{ 8th graders } \\
\hline & $\begin{array}{c}\mathrm{Q}^{*} \\
(n=29) \dagger\end{array}$ & $\begin{array}{c}\mathrm{Q}^{*} \\
(n=45)\end{array}$ & $P$-value $\ddagger$ & $\begin{array}{c}\mathrm{Q}^{*} \\
(n=69) \dagger\end{array}$ & $\begin{array}{c}\mathrm{Q}^{*} \\
(n=103)\end{array}$ & $P$-value $\ddagger$ & $\begin{array}{c}\mathrm{Q}^{*} \\
(n=96) \dagger\end{array}$ & $\begin{array}{c}\mathrm{Q}^{*} \\
(n=112)\end{array}$ & $P$-value $\ddagger$ \\
\hline $\mathrm{BMI}\left(\mathrm{kg} \mathrm{m}^{-2}\right)$ & $15.7(1.5)$ & $16.1(1.7)$ & 0.341 & $17.4(2.8)$ & $16.8(3.0)$ & 0.236 & $19.4(3.1)$ & $18.5(2.2)$ & 0.013 \\
\hline Overweight (\%) & 13.8 & 9.1 & 0.529 & 21.2 & 15.5 & 0.346 & 11.5 & 7.1 & 0.282 \\
\hline $\mathrm{El} / \mathrm{BMR}<1.06(\%)$ & 0 & 4.4 & 0.250 & 7.2 & 5.8 & 0.709 & 22.0 & 18.6 & 0.538 \\
\hline
\end{tabular}

$\mathrm{BMI}$ - body mass index; EI - energy intake; BMR - basal metabolic rate.

${ }^{*}$ First and fourth quartile of percentage of energy consumed from added sugar.

†Two-sample $t$-test for BMI and Chi-square test for \% overweight.

$\ddagger$ Numbers of children in the two quartiles (Q1 and Q4) differ since not all children gave data on their weight and height.

Table 6 Distribution of BMI (mean (standard deviation)) and percentage of overweight and underreporters among low and high added sugar consumers (boys)

\begin{tabular}{|c|c|c|c|c|c|c|c|c|c|}
\hline & \multicolumn{3}{|c|}{ 4-year-olds } & \multicolumn{3}{|c|}{ 4th graders } & \multicolumn{3}{|c|}{ 8th graders } \\
\hline & $\begin{array}{c}\mathrm{Q}^{*} \\
(n=36) \dagger\end{array}$ & $\begin{array}{c}\mathrm{Q}^{*} \\
(n=32)\end{array}$ & $P$-value $\neq$ & $\begin{array}{c}\mathrm{Q}^{*} \\
(n=103) \dagger\end{array}$ & $\begin{array}{c}\mathrm{Q}^{*} \\
(n=80)\end{array}$ & $P$-value $\ddagger$ & $\begin{array}{c}\mathrm{Q}^{*} \\
(n=107) \dagger\end{array}$ & $\begin{array}{c}\mathrm{Q}^{*} \\
(n=101)\end{array}$ & $P$-value $\ddagger$ \\
\hline BMI $\left(\mathrm{kg} \mathrm{m}^{-2}\right)$ & $15.7(1.3)$ & $16.3(1.4)$ & 0.055 & $16.8(2.5)$ & $17.2(2.8)$ & 0.312 & 18.9 (2.3) & $18.9(2.7)$ & 0.816 \\
\hline Overweight (\%) & 5.7 & 13.3 & 0.290 & 14.6 & 22.7 & 0.173 & 10.6 & 10.3 & 0.951 \\
\hline $\mathrm{El} / \mathrm{BMR}<1.06(\%)$ & 2.8 & 0 & 0.342 & 6.8 & 7.5 & 0.854 & 27.1 & 24.8 & 0.699 \\
\hline
\end{tabular}

BMI - body mass index; EI - energy intake; BMR - basal metabolic rate.

${ }^{*}$ First and fourth quartile of percentage of energy consumed from added sugar.

$\dagger$ Two-sample $t$-test for BMI and Chi-square test for \% overweight.

$\ddagger$ Numbers of children in the two quartiles (Q1 and Q4) differ since not all children gave data on their weight and height.

than did mothers of high added sugar consumers (45\%)

(Table 7). No significant association between energy intake from added sugar and parental education was observed among 4th- and 8th-grade students.
There were no significant differences between low and high added sugar consumers with regard to time spent on physical leisure activity, although it was of borderline significance for 4th graders. Among 8th graders there was

Table 7 Parental education, physical activity and inactivity for low and high added sugar consumers

\begin{tabular}{|c|c|c|c|c|c|c|c|c|c|}
\hline & \multicolumn{3}{|c|}{ 4-year-olds } & \multicolumn{3}{|c|}{4 th graders } & \multicolumn{3}{|c|}{ 8th graders } \\
\hline & $\begin{array}{c}\mathrm{Q}^{*} \\
(n=97)\end{array}$ & $\begin{array}{c}\mathrm{Q}^{*} \\
(n=98)\end{array}$ & $P$-value $†$ & $\begin{array}{c}\mathrm{Q1}^{*} \\
(n=202)\end{array}$ & $\begin{array}{c}\mathrm{Q}^{*} \\
(n=202)\end{array}$ & $P$-value $†$ & $\begin{array}{c}\mathrm{Q}^{*} \\
(n=251)\end{array}$ & $\begin{array}{c}\mathrm{Q} 4^{*} \\
(n=251)\end{array}$ & $P$-value $\dagger$ \\
\hline \multicolumn{10}{|l|}{ Mother's education (\%)‡ } \\
\hline$<13$ years & 39 & 55 & 0.048 & 58 & 63 & 0.276 & 65 & 70 & 0.254 \\
\hline$\geq 13$ years & 61 & 45 & & 42 & 37 & & 35 & 30 & \\
\hline \multicolumn{10}{|l|}{ Father's education (\%)§ } \\
\hline$<13$ years & 44 & 57 & 0.116 & 59 & 68 & 0.084 & 61 & 65 & 0.403 \\
\hline$\geq 13$ years & 57 & 43 & & 41 & 32 & & 39 & 35 & \\
\hline \multicolumn{10}{|c|}{ Leisure-time physical activity (\%)ף } \\
\hline$<1$ time per week & - & - & - & 2 & 3 & & 10 & 8 & \\
\hline $1-3$ times per week & - & - & - & 35 & 46 & 0.066 & 62 & 59 & 0.518 \\
\hline$\geq 4$ times per week & - & - & - & 63 & 51 & & 28 & 33 & \\
\hline \multicolumn{10}{|l|}{ |nactivity (\%)|| } \\
\hline $\begin{array}{l}\text { Watch TV/use PC for } 1 \mathrm{~h} \\
\text { or less per day }\end{array}$ & 93 & 85 & & 65 & 58 & & 35 & 22 & \\
\hline $\begin{array}{l}\text { Watch TV/use PC for } \\
2-3 \mathrm{~h} \text { per day }\end{array}$ & 7 & 14 & 0.243 & 33 & 40 & 0.352 & 48 & 55 & 0.010 \\
\hline $\begin{array}{l}\text { Watch TV/use PC for } \\
4 \mathrm{~h} \text { or more per day }\end{array}$ & 0 & 1 & & 2 & 2 & & 17 & 22 & \\
\hline
\end{tabular}

${ }^{*}$ First and fourth quartile of percentage of energy consumed from added sugar.

†Chi-square test.

¥ Missing data: among 4-year-olds, data are missing for 26 (Q1) and 13 (Q4) persons; among 4th graders, for 24 (Q1) and 16 (Q4) persons; and among 8th graders, for 53 (Q1) and 35 (Q4) persons.

$\S$ Missing data: among 4-year-olds, data are missing for 25 (Q1) and 17 (Q4) persons; among 4th graders, for 31 (Q1) and 24 (Q4) persons; and among 8th graders, for 62 (Q1) and 43 (Q4) persons.

II Missing data: among 4th graders, data are missing for 20 (Q1) and 11 (Q4) persons; and among 8th graders, for 29 (Q1) and 19 (Q4) persons.

|| Missing data: among 4-year-olds, data are missing for 26 (Q1) and 12 (Q4) persons; among 4th graders, for 22 (Q1) and 12 (Q4) persons; and among 8th graders, for 29 (Q1) and 19 (Q4) persons. 
an association between time spent watching TV/using a PC and sugar intake for the whole group, and for boys separately. This was not observed for 4 -year-olds and the 4 th graders.

\section{Discussion}

The present study shows a negative association between intake of added sugar and intakes of micronutrients. For fibre and several micronutrients, the intake was lower than the recommendations in the highest quartile of added sugar intake. Moreover, a negative association between added sugar and fruit and vegetables was observed. The children with the highest added sugar intake had a 30$40 \%$ lower intake of fruit and vegetables than those with low intake of added sugar. A negative association was observed between consumption of added sugar and BMI among girls in the 8th grade, while a borderline significant positive association was observed between BMI and intake of sugar among 4-year-old boys.

Compared with the recommendation of a maximum of $10 \%$ of energy from added sugar, the intake of energy from added sugar was on average high for all age groups (15$18 \%$ of energy) in this study. There seems to have been an increase in the intake of sugar among Norwegian adolescents during the past few years. In a Norwegian nation-wide study from 1993, 13-year-old children had an intake of $11 \%$ of energy from added sugar ${ }^{20}$. In Danish surveys from $1999^{6}$ and $2000^{21}$, children aged $4-14$ years had a somewhat lower energy intake from added sugar (13-14\%) compared with Norwegian children. Similar levels were observed among Swedish 4-14-year-olds ${ }^{22}$ and German 4-6-year-olds ${ }^{8}$. British children aged 4-18 years had a sugar intake of $18 \%$ of energy ${ }^{23}$, which is similar to what was found among Norwegian children. These figures indicate that the intake of sugar is much higher than recommended in many countries; however, the consequence of this high intake on the quality of the diet is still unclear.

Several researchers have reported higher intakes of essential nutrients with increasing percentage of energy from sugar ${ }^{1-3}$ and increasing intake of sugar $\left(\text { g day }^{-1}\right)^{4,5}$. This effect may be logical if increased sugar intake is linked to higher intake of energy. However, when energy intake does not differ with sugar intake as in the present study, a clear negative effect on nutrient density has been observed with increasing energy intake from sugar ${ }^{2,6-8}$. Even if our results support the concept of the 'displacement theory' and the percentage decreases in intakes of nutrients from low to high added sugar consumers are substantial, the nutritional consequences of increasing added sugar in the diet differ strongly from one nutrient to another and across age groups. Among 4-year-olds the intakes of several micronutrients were at the recommended level even in the highest quartile of sugar intake, while this was only the case for vitamin $\mathrm{C}$ among 8th graders. Moreover, the intakes of dietary fibre, vitamin $\mathrm{D}, \alpha$-tocopherol and iron were below recommended levels in all four quartiles and age groups. For these three nutrients and fibre it is even more severe when the intake decreases with increasing added sugar intake.

In the present study intake of added sugar does not seem to have an effect on the intake of vitamin $\mathrm{C}$, an effect that has also been observed by others ${ }^{5,6}$. The explanation for this is that sweetened lemonade actually contributes with vitamin C. About $25 \%$ of the vitamin C intake among the high consumers of added sugar derived from lemonade in our study. Among the low added sugar consumers, only $7 \%$ of the vitamin $\mathrm{C}$ intake derived from lemonade.

It is well known that high intakes of fruit and vegetables have a positive health effect, especially in relation to cancer and cardiovascular disease ${ }^{12,13}$. Generally, the intake of fruit and vegetables was low in all age groups compared with the recommendation of 5 portions of fruit and vegetables a day $\left(\approx 500 \mathrm{~g} \mathrm{day}^{-1}\right.$ for children). Furthermore, we observed a negative association between intake of fruit and vegetables and added sugar for all age groups. Intake of fruit and vegetables among low added sugar consumers was 55-63\% of the recommended intake, while the corresponding value was $35-39 \%$ for the high added sugar consumers. For vegetables alone there was a $45 \%$ decrease in intake from low to high added sugar consumers among 4-year-olds and 8th graders. Forshee and Storey ${ }^{5}$ found similar results for fruit, but not for vegetables, among adolescents aged 12-19 years. In the study by Lewis et $a l^{2}$ among 4-10-year-olds, no association was observed between percentage of energy from sugar and fruit and vegetables. The same was found by Rugg-Gunn et $a{ }^{1}{ }^{1}$ among 11-14-year-olds, except among boys. Boys with high sugar consumption, expressed as $\mathrm{g} \mathrm{MJ}^{-1}$, had a lower intake of vegetables than did those with a low sugar intake. A Norwegian longitudinal cohort study from age 14 to age 21 showed that low consumption of fruit and vegetables, as observed in our study, may persist into adulthood ${ }^{24}$ and continue to have a negative effect on health.

In our study, $50-70 \%$ of the added sugar derived from soft drinks and sweets. Similar figures were found in a Danish study by Lyhne and Ovesen ${ }^{6}$ and in two American studies, by Guthrie and Morton ${ }^{25}$ and Gibney et al. ${ }^{4}$. Soft drinks and sweets are characterised by a low content of micronutrients and may explain the negative association between intake of added sugar and nutrient intake. Soft drinks alone contributed on average $40 \%$, and among the boys in the 8 th grade $46 \%$, of the added sugar.

To our knowledge, only one study ${ }^{2}$ has evaluated the association between BMI and added sugar among children and adolescents. Lewis et $a l^{2}$ found that children aged 4-10 years and 11-18 years with a moderate percentage of energy from added sugar weighed more than did children with a high consumption of added sugar. Gibson ${ }^{3}$ also 
found an inverse relationship between BMI and total sugar intake $\left(\mathrm{g} \mathrm{day}^{1}\right)$ among adolescents. However, in this study sugar also included sugar from fruit and milk ${ }^{3}$. These studies are in agreement with what we observed among the 8th-grade girls: i.e. girls in the highest added sugar quartile had a lower BMI than girls in the lowest quartile. Among 4-year-old boys we found the opposite association, that the boys in the highest quartile of added sugar intake had a borderline significant higher BMI than boys in the lowest quartile. A positive association between sugar intake and BMI among young children has not been reported previously. However, the study by Ludwig et al. supports the hypothesis that sugar may play a role in increased body weight ${ }^{15}$. They examined the relationship between consumption of sugar-sweetened soft drinks and childhood obesity, and found that, for each additional serving of sugar-sweetened drink consumed, the odds of becoming obese increased by $60 \%{ }^{15}$. The differences in BMI observed in the present study for both girls in the 8th grade and 4-year-old boys across added sugar quartiles could not be explained by differences in energy intake, since energy intake did not differ across quartiles. Moreover, no difference in underreporting of energy intake across the added sugar quartiles was found in the two age groups. Physical activity could be an important explanatory variable according to difference in BMI. However, there were no differences in physical activity of 8th-grade girls between the lowest and highest added sugar quartiles, and no physical activity was reported among the 4-year-olds. It is important to notice the limitations of our study, which include the dietary data and data on weight and height being self-reported. This can disturb the true relationship between sugar intake and BMI. Furthermore, only $70-80 \%$ of the participants gave data on height and weight. Among the 4-year-olds data on weight and height were measured at the child health centre and recorded there, which should imply that these data are more reliable than those from the 4th- and 8thgrade students. The cross-sectional nature of the data limits, of course, our ability to evaluate causality.

We found an association between mothers' education and 4-year-olds' intake of sugar. Among low added sugar consumers there was a larger percentage of mothers with long education compared with high consumers. Similar results were found in the study by Cullen et al. ${ }^{26}$, where students of parents with shorter education consumed more soft drinks and total sweetened beverages than did students of parents with longer education. The same association was not observed for 4th and 8th graders, which might imply that parental influence becomes less important at this age. Neither did we find any association between physical activity and sugar intake, but among 8th graders there were more students among the high added sugar consumers who watched TV/used a PC for $4 \mathrm{~h}$ or more per day compared with low added sugar consumers.

\section{Conclusion}

In conclusion, the present study shows that the high intake of added sugar among Norwegian children and adolescents has a negative effect on the intakes of micronutrients and the intake of fruit and vegetables. The negative association between sugar intake and intake of fruit and vegetables is important from a public health perspective, since one of the main health messages today is to increase current intake of fruit and vegetables. The negative association observed between BMI and sugar intake among 8th-grade girls found in the present study supports results reported in other studies. However, the positive association observed between high intake of added sugar and BMI among 4-year-old boys has not been shown previously. More studies are required among young children in relation to added sugar intake and BMI.

\section{Acknowledgements}

This study was supported by the Directorate for Health and Social Affaires and the Norwegian Food Control Authority. The authors would like to express their appreciation and acknowledge the contributions of Elin Bjørge Løken, Kari Lund Larsen and Christina Bergsten in developing the methods used in this study.

\section{References}

1 Rugg-Gunn AJ, Hackett AF, Jenkins GN, Appleton DR. Empty calories? Nutrient intake in relation to sugar intake in English adolescents. Journal of Human Nutrition and Dietetics 1991; 4: 101-11.

2 Lewis CJ, Park YK, Dexter PB, Yetley EA. Nutrient intakes and body weights of persons consuming high and moderate levels of added sugars. Journal of the American Dietetic Association 1992; 92: 708-13.

3 Gibson SA. Consumption and sources of sugars in the diets of British schoolchildren: are high-sugar diets nutritionally inferior? Journal of Human Nutrition and Dietetics 1993; 6: $355-71$.

4 Gibney M, Sigman-Grant M, Stanton JL, Keast DR. Consumption of sugars. American Journal of Clinical Nutrition 1995; 62: 178S-94S.

5 Forshee RA, Storey ML. The role of added sugars in the diet quality of children and adolescents. Journal of the American College of Nutrition 2001; 20: 32-43.

6 Lyhne N, Ovesen L. Added sugars and nutrient density in the diet of Danish children. Scandinavian Journal of Nutrition 1999; 43: 4-7.

7 Farris RP, Nicklas TA, Myers L, Berenson GS. Nutrient intake and food group consumption of 10-year-olds by sugar intake level: The Bogalusa Heart Study. Journal of the American College of Nutrition 1998; 17: 579-85.

8 Linseisen J, Gedrich K, Karg G, Wolfram G. Sucrose intake in Germany. Zeitschrift fur Ernährungwissenschaft 1998; 37: 303-14.

9 Nordic Council of Ministers. Nordic Nutrition Recommendations 1996. Copenhagen: Nordisk Forlagshus, 1996.

10 Ruxton CHS, Garceau FJS, Cotrell RC. Guidelines for sugar consumption in Europe: is a quantitative approach justified? European Journal of Clinical Nutrition 1999; 53: 503-13. 
11 Johnson RK, Frayry C. Choose beverages and foods to moderate your intake of sugars: the 2000 dietary guidelines for Americans - what's all the fuss about? Journal of Nutrition 2001; 131: 2766S-71S.

12 World Cancer Research Fund (WCRF)/American Institute for Cancer Research (AICR). Food, Nutrition and the Prevention of Cancer: A Global Perspective. Washington, DC: WCRF/AICR, 1997.

13 Law MR. By how much does fruit and vegetable consumption reduce the risk of ischaemic heart disease? European Journal of Clinical Nutrition 1998; 52: 549-56.

14 Kohn M, Booth M. The worldwide epidemic of obesity in adolescents. Adolescent Medicine 2003; 14: 1-99.

15 Ludwig DS, Peterson KE, Gortmaker SL. Relation between consumption of sugar-sweetened drinks and childhood obesity: a prospective, observational analysis. Lancet 2001; 357: 505-8.

16 Rimestad AH, Løken EB, Nordbotten A. Den norske matvaretabellen og beregningsdatabasen ved Institutt for ernæringsforskning [in Norwegian]. Norsk Epidemiologi 2000; 10: 7-10.

17 Food and Agriculture Organization/World Health Organization (WHO)/United Nations University. Energy and Protein Requirements. Report of Joint Expert Consultation. Technical Report Series No. 724. Geneva: WHO, 1985.

18 Goldberg GR, Black AE, Jebb SA, Cole TJ, Murgatroyd PR, Coward WA, et al. Critical evaluation of energy intake data using fundamental principles of energy physiology: 1 . Derivation of cut-off limits to identify under-recording. European Journal of Clinical Nutrition 1991; 45: 569-81.
19 Cole TJ, Bellizzi MC, Flegal KM, Dietz WH. Establishing a standard definition for child overweight and obesity worldwide: international survey. British Medical Journal 2000; 320: 1-6.

20 Andersen LF, Nes M, Sandstad B, Bjorneboe GE, Drevon CA. Dietary intake among Norwegian adolescents. European Journal of Clinical Nutrition 1995; 49(8): 555-64.

21 Fagt S, Matthessen J, Trolle E, Lyhne N, Christensen T, Hinsch HJ, et al. Dietary Habits of the Danish Population 2001-2002. Fødevaredirektoratet, Afdeling for Ernæring. Copenhagen: Silkeborg bogtryk, 2002 [in Danish].

22 Becker W. Dietary and Nutrient Intake in the Swedish Population 1989. Uppsala: Statens Livsmedelsverk, 1994 [in Swedish].

23 Gregory J, Lowe S, Bates CJ, Prentice A, Jackson LV, Smithers G, et al. National Diet and Nutrition Survey: Young People aged 4 to 18 years. Volume 1: Report of the Diet and Nutrition Survey. London: The Stationery Office, 2000.

24 Lien N, Lytle L, Klepp K-I. Stability in consumption of fruits, vegetables, and sugary foods in cohort from age 14 to 21 . Preventive Medicine 2001; 33: 217-26.

25 Guthrie JF, Morton JF. Food sources of added sweeteners in the diets of Americans. Journal of the American Dietetic Association 2000; 100: 43-51.

26 Cullen KW, Ash DM, Warneke C, de Moor C. Intake of soft drinks, fruit-flavored beverages, and fruits and vegetables by children in grades 4 through 6. American Journal of Public Health 2002; 9: 1475-8. 